\title{
Psychological characteristics of and counseling for carriers of structural chromosome abnormalities
}

\author{
H.L. Wang ${ }^{1}$, B. Wu ${ }^{2}$, K.M. Guo ${ }^{1}$ and R.H. Tian ${ }^{3}$ \\ ${ }^{1}$ Department of Andrology, First Hospital of Jilin University, \\ Changchun, Jilin Province, China \\ 2Department of Psychology, Sixth People's Hospital of Changchun, \\ Jilin Province, China \\ ${ }^{3}$ Department of Psychology, First Hospital of Jilin University, \\ Changchun, Jilin Province, China \\ Corresponding author: R.H. Tian \\ E-mail: tianrhjdyy@126.com
}

Genet. Mol. Res. 15 (2): gmr.15028159

Received November 26, 2015

Accepted January 18, 2016

Published April 26, 2016

DOI http://dx.doi.org/10.4238/gmr.15028159

\begin{abstract}
Infertility as a psychological problem has gained increasing attention. Male partners among infertile couples have elevated levels of psychological distress, which could affect semen quality, result in hormonal abnormalities, and increase the occurrence of early miscarriage. Infertile women are more vulnerable to psychological distress and require psychological support. Subfertile women who conceive after assisted reproduction have higher stress, anxiety, and depression levels. Psychological interventions have been shown to have beneficial effects on infertility patients. However, psychosocial characteristics of carriers of structural chromosome abnormalities have not been studied. We report the characteristics of carriers of structural chromosome abnormalities and their influence on psychological counseling. Seventy-five patients were carriers of reciprocal translocations, 25 carried Robertsonian translocations, 17
\end{abstract}


carried inversions, 10 carried deletions, and 3 carried isochromosomes. The main clinical characteristics were recurrent spontaneous abortion, oligospermatism, azoospermatism, primary amenorrhea, and fetal death. Self-rating anxiety scale (SAS) and self-rating depression scale (SDS) scores of women with structural chromosome abnormality were significantly higher than those scores of women with normal karyotype. SAS and SDS scores of men with structural chromosome abnormality were significantly higher than those of men with normal karyotype. SAS and SDS scores of women with structural chromosome abnormality were significantly higher than their scores of men with structural chromosome abnormality. Women carriers with structural chromosome abnormality were more vulnerable to psychological distress. Psychosocial counseling for carriers of structural chromosome abnormalities should focus on self-confidence and treatment with assisted reproductive technology.

Key words: Infertility; Structural chromosome abnormality; Anxiety and depression; Psychological counseling

\section{INTRODUCTION}

Infertility is a multidisciplinary problem, and infertile patients require the best diagnostic, therapeutic, and psychosocial services (Li et al., 2014). Recently, infertility as a psychological problem (Podolska and Bidzan, 2011) has received an increasing amount attention (Bak et al., 2012). The frustration of infertile couples leads to not only anxiety and depression but also negative effects on relationships (Bak et al., 2012). Depression was reported by $48 \%$ of women and $23.8 \%$ of men (Noorbala et al., 2008). Infertile couples' rates of significant anxiety symptoms $(24.2 \%)$ and depressive symptoms $(20.0 \%)$ were higher than the corresponding rates of $13.7 \%$ and $9.5 \%$ for controls (Fatoye et al., 2009). Male partners among infertile couples experience elevated levels of psychological distress (Dyer et al., 2009). Infertile men had lower self-esteem, higher anxiety, and showed more somatic symptoms than fertile men (Kedem et al., 1990). Gana and Jakubowska (2014) reported that their findings confirmed the predictive effects of infertility-related stress on both emotional and marital distress. Psychological interventions have been shown to have beneficial effects for patients with infertility (Cousineau and Domar, 2007).

Psychological distress could affect semen quality, resulting in hormonal abnormalities, and increase the occurrence of early miscarriage. Gollenberg et al. (2010) reported that stressful life events may be associated with decreased semen quality in fertile men. Serum total testosterone correlated negatively with hospital anxiety and depression score (HADS), but luteinizing hormone (LH) and follicle-stimulating hormone (FSH) correlated positively. Sperm count, motility, and morphologically normal spermatozoa were lower in persons with abnormal HADS. Psychological stress primarily lowers serum total testosterone levels, with secondary increases in serum LH and FSH levels altering seminal quality (Bhongade et al., 2015). Depression in men is possibly related to decreased sperm concentration, and poor coping with stress is associated with increased occurrence of early miscarriage (Zorn et al., 2008). 
Psychosocial characteristics of couples who conceived after assisted reproduction have gained more attention. After first-trimester miscarriage, subfertile women who conceived after assisted reproduction had higher stress, anxiety, and depression levels, and they experienced more traumatic effects from the event than did women who conceived naturally (Cheung et al., 2013). In vitro fertilization (IVF) failure predicts subsequent psychological distress, but preIVF psychological distress does not predict IVF failure. These findings suggest that instead of focusing efforts on psychological interventions specifically aimed at improving the chance of pregnancy, attention should be given to help patients prepare for and cope with treatment and treatment failure (Pasch et al., 2012).

However, psychosocial characteristics of carriers of structural chromosome abnormalities have not been studied. The effects of structural chromosome abnormalities depend on whether they are present in balanced or unbalanced forms. The carriers of balanced forms may show variable sperm counts, ranging from normal counts to low counts, or even a total absence of sperm in the ejaculate (Venkateshwari et al., 2011). Hence, psychological characteristics and counseling of these patients may be more complex. In this study, psychological characteristics of carriers of structural chromosome abnormalities in Jilin Province, China, and their implications in psychological counseling are reported.

\section{MATERIAL AND METHODS}

\section{Patients}

Couples who sought prepregnancy counseling in the Andrology Outpatient's Clinic of the First Hospital of Jilin University from January 2012 to June 2015 were consecutively recruited for this study. One-hundred thirty couples were recruited, including 72 men and 58 women with structural chromosome abnormalities. One partner was the carrier of the structural chromosome abnormality among all couples. Couples with normal karyotypes were recruited as a control group, which included 102 men and 82 women.

\section{Questionnaire}

An elaborate questionnaire was provided to each subject to collect their information, including age, marital history, educational status, monthly income, smoking history and frequency, alcohol consumption, occupational status, and medical history.

\section{Evaluation of anxiety and depression}

Anxiety and depression were evaluated by the self-rating anxiety scale (SAS) and self-rating depression scale (SDS), respectively. Two indices were included by using the Chinese versions of SAS and SDS, which Gao et al. (2013) reported. According to Gao et al. (2013), those with SAS $\geq 50$ and SDS $\geq 53$ were diagnosed as having anxiety and depression, respectively.

\section{Cytogenetic analysis}

Peripheral blood from all subjects was collected in sterile tubes containing $30 \mathrm{U} /$ 
$\mathrm{mL}$ heparin. G-banding was performed using cultured peripheral blood lymphocytes, and the karyotypes of metaphases were analyzed for each subject (Zhang et al., 2015).

\section{Statistical analysis}

All data were analyzed using SPSS v.17.0 for Windows (SPSS, Inc, Chicago, IL, USA). Parametric variables were compared by independent sample $t$-tests. All results were reported as means $\pm \mathrm{SD} . \mathrm{P}<0.05$ was considered to be statistically significant.

\section{RESULTS}

The types of structural chromosome abnormalities and clinical characteristics are shown in Table 1. Of the 72 men, 58.3\% (42/72) carried reciprocal translocations, 22.2\% (16/72) carried Robertsonian translocations, 11.1\% (8/72) carried inversions, 6.9\% (5/72) carried deletions, and 1.4\% (1/72) carried isochromosomes. Clinical characteristics included $43.1 \%$ (31/72) with recurrent spontaneous abortions, $23.6 \%$ (17/72) with oligospermatism, $19.4 \%$ $(14 / 72)$ with azoospermatism, and $13.9 \%$ (10/72) with fetal deaths. Of the 58 women, $56.9 \%$ (33/58) carried reciprocal translocations, $15.5 \%(9 / 58)$ carried Robertsonian translocations, $15.5 \%(9 / 58)$ carried inversions, $8.6 \%(5 / 58)$ carried deletions, and 3.4\% $(2 / 58)$ carried isochromosomes. Clinical characteristics include $58.6 \%(34 / 58)$ with recurrent spontaneous abortions, $31.0 \%(18 / 58)$ with fetal deaths, and $10.3 \%(6 / 58)$ with primary amenorrhea.

\begin{tabular}{|c|c|c|c|}
\hline \multirow[t]{2}{*}{ Gender (N) } & \multicolumn{2}{|c|}{ Structural abnormality } & \multirow[t]{2}{*}{ Clinical characteristics (cases) } \\
\hline & Type & Cases & \\
\hline \multirow[t]{5}{*}{ Male (72) } & Reciprocal translocation & 42 & Recurrent spontaneous abortion (31), oligospermatism (17), azoospermatism \\
\hline & Robertsonian translocation & 16 & \multirow[t]{4}{*}{ (14), fetal death (10) } \\
\hline & Inversion & 8 & \\
\hline & Deletion & 5 & \\
\hline & Isochromosome & 1 & \\
\hline \multirow[t]{5}{*}{ Female (58) } & Reciprocal translocation & 33 & \multirow[t]{5}{*}{ Recurrent spontaneous abortion (34), fetal death (18), primary amenorrhea (6) } \\
\hline & Robertsonian translocation & 9 & \\
\hline & Inversion & 9 & \\
\hline & Deletion & 5 & \\
\hline & Isochromosome & 2 & \\
\hline
\end{tabular}

Table 2 shows that SAS and SDS scores of women with structural chromosome abnormalities were significantly higher than the scores of women with normal karyotypes $(\mathrm{P}<0.001)$. Table 3 shows that SAS and SDS scores of women with structural chromosome abnormalities were significantly higher than the scores of men with structural chromosome abnormalities $(\mathrm{P}<0.05$ and $\mathrm{P}<0.01$ respectively). Table 4 shows that SAS and SDS scores of men with structural chromosome abnormalities were significantly higher than scores of men with normal karyotypes $(\mathrm{P}<0.001)$.

Table 2. Self-rating anxiety scale (SAS) and self-rating depression scale (SDS) scores of women with structural
chromosome abnormalities.
\begin{tabular}{l|c|c|c}
\hline Characteristics & Women with normal karyotypes (82) & Women with structural chromosome abnormalities $(58)$ & P \\
\hline SAS scores & $47.80 \pm 6.19$ & $54.41 \pm 8.52$ & $0.000^{*}$ \\
\hline SDS scores & $50.41 \pm 6.72$ & $58.34 \pm 7.70$ & $0.000^{*}$ \\
\hline$* \mathrm{P}<0.001$
\end{tabular}

$* \mathrm{P}<0.001$ compared to women with normal karyotypes. 
Table 3. Self-rating anxiety scale (SAS) and self-rating depression scale (SDS) scores of men and women with structural chromosome abnormalities.

\begin{tabular}{l|c|c|c}
\hline Characteristics & Men with structural chromosome abnormalities (72) & Women with structural chromosome abnormalities $(58)$ & $\mathrm{P}$ \\
\hline SAS scores & $51.42 \pm 5.84$ & $54.41 \pm 8.52$ & $0.025^{*}$ \\
\hline SDS scores & $54.43 \pm 5.27$ & $58.34 \pm 7.70$ & $0.002^{* *}$ \\
\hline
\end{tabular}

$* \mathrm{P}<0.05$ and $* * \mathrm{P}<0.01$ compared to women with structural chromosome abnormalities.

Table 4. Self-rating anxiety scale (SAS) and self-rating depression scale (SDS) of men with structural chromosome abnormality.

\begin{tabular}{l|c|c|c}
\hline Characteristics & Men with normal karyotypes (102) & Men with structural chromosome abnormalities (72) & P \\
\hline SAS scores & $46.70 \pm 6.72$ & $51.42 \pm 5.84$ & $0.000^{*}$ \\
\hline SDS scores & $48.76 \pm 7.29$ & $54.43 \pm 5.27$ & $0.000^{*}$ \\
\hline
\end{tabular}

$* \mathrm{P}<0.001$ compared to men with normal karyotypes.

\section{DISCUSSION}

The inability to conceive children is a stressful situation experienced by individuals and couples all around the world (Cousineau and Domar, 2007). Infertile couples express the need for psychosocial support, but they often feel that support is not available (Read et al., 2014). Timely support and psychological intervention would be beneficial in the management of infertile couples (Cheung et al., 2013).

Physicians and clinicians should acknowledge the immense psychosocial effects of the diagnosis of infertility in men on both men and their fertile women partners (Bak et al., 2012). Understanding the psychological mechanisms observed in patients treated for infertility might help in their diagnoses and might help them face this new and extremely difficult situation (Podolska and Bidzan, 2011). In this study, we examined the psychological characteristics of carriers of structural chromosome abnormalities. Seventy-five patients were carriers of reciprocal translocations, 25 carried Robertsonian translocations, 17 carried inversions, 10 carried deletions, and 3 carried isochromosomes. For male carriers, the main clinical characteristics were recurrent spontaneous abortion, oligospermatism, azoospermatism, and fetal death. For female carriers, the main clinical characteristics were recurrent spontaneous abortion, fetal death, and primary amenorrhea.

Infertile couples seeking psychological help are characterized by high levels of psychological distress. Infertile women are more vulnerable to psychological distress and require psychological support (Wischmann et al., 2009; Klemetti et al., 2010; Omoaregba et al., 2011). Infertile women experience various problems, including being childless, negative self-concept, and psychological symptoms (Karaca and Unsal, 2015). For Malaysian infertile couples, significantly higher frequencies of depression, anxiety, and stress-related difficulties were reported by wives than by husbands (Musa et al., 2014). Severe depressive symptoms were reported by $11.6 \%$ of women and by $4.3 \%$ of men, and they were significantly associated with increased infertility-related distress at individual and partner levels (Peterson et al., 2014). In this study, SAS and SDS scores of women with structural chromosome abnormalities were significantly higher than the scores of women with normal karyotypes. SAS and SDS scores of women with structural chromosome abnormalities were significantly higher than scores of men with structural chromosome abnormalities. Female carriers of structural chromosome abnormalities are more vulnerable to psychological distress and require psychological support. 
Research concerning the psychosocial aspects of infertility and infertility treatment more often focuses on women than on men (Fisher and Hammarberg, 2012). Infertile men who are socially isolated, have an avoidant coping style, and appraise stressful events as overwhelming are more vulnerable to severe anxiety than men without these characteristics. Men prefer oral to written treatment information and prefer to receive emotional support from infertility clinicians rather than from mental health professionals, self-help support groups, or friends (Fisher and Hammarberg, 2012). In this study, SAS and SDS scores of men with structural chromosome abnormalities were significantly higher than scores of men with normal karyotypes.

Psychosocial counseling for carriers of structural chromosome abnormalities should focus on increased self-confidence and timely treatment with assisted reproductive technology. High infertility-related stress levels before beginning fertility treatment can negatively affect the stability of marital relationships and lead to repartnering (Martins et al., 2014). Psychosocial interventions for couples undergoing treatment for infertility could be efficacious for reducing psychological distress and for improving clinical pregnancy rates (Frederiksen et al., 2015). The cumulative live birth rate is $64.3 \%$ for couples in which either partner has a chromosomal anomaly and who have experienced repeated miscarriage (Flynn et al., 2014). The success rates of natural pregnancies range from $30 \%$ to $70 \%$ for men carrying translocations (Ozawa et al., 2008). Based on the effectiveness of psychiatric interventions for increasing pregnancy rates, it is crucial to mandate psychiatric counseling at all fertility centers to diagnose and treat infertile patients with psychiatric disorders (Ramezanzadeh et al., 2011). IVF accompanied by preimplantation genetic diagnosis increases pregnancy rates for carriers of balanced chromosomal translocations (Vozdova et al., 2011).

\section{CONCLUSIONS}

In summary, the reciprocal translocations were most commonly structural chromosome abnormalities in Jilin Province, China. The main clinical characteristics were recurrent spontaneous abortion, fetal death, oligospermatism, azoospermatism, and primary amenorrhea. Psychological distress should be taken seriously for carriers of structural chromosome abnormalities. Psychosocial counseling for carriers of structural chromosome abnormalities should focus on increased selfconfidence and timely treatment with assisted reproductive technology.

\section{Conflicts of interest}

The authors declare no conflict of interest.

\section{ACKNOWLEDGMENTS}

We express our sincere gratitude to all the staff of the Genetics Laboratory of First Hospital of Jilin University for their excellent work.

\section{REFERENCES}

Bak CW, Seok HH, Song SH, Kim ES, et al. (2012). Hormonal imbalances and psychological scars left behind in infertile men. J. Androl. 33: 181-189. http://dx.doi.org/10.2164/jandrol.110.012351

Bhongade MB, Prasad S, Jiloha RC, Ray PC, et al. (2015). Effect of psychological stress on fertility hormones and seminal quality in male partners of infertile couples. Andrologia 47: 336-342. http://dx.doi.org/10.1111/and.12268 
Cheung CS, Chan $\mathrm{CH}$ and $\mathrm{Ng}$ EH (2013). Stress and anxiety-depression levels following first-trimester miscarriage: a comparison between women who conceived naturally and women who conceived with assisted reproduction. BJOG 120: 1090-1097. http://dx.doi.org/10.1111/1471-0528.12251

Cousineau TM and Domar AD (2007). Psychological impact of infertility. Best Pract. Res. Clin. Obstet. Gynaecol. 21: 293-308. http://dx.doi.org/10.1016/j.bpobgyn.2006.12.003

Dyer S, Lombard C and Van der Spuy Z (2009). Psychological distress among men suffering from couple infertility in South Africa: a quantitative assessment. Hum. Reprod. 24: 2821-2826. http://dx.doi.org/10.1093/humrep/dep278

Fatoye FO, Eegunranti BA, Owolabi AT and Fatoye GK (2009). Psychological profile of spouses of women with infertility in Nigeria. Afr. J. Med. Med. Sci. 38: 63-69.

Fisher JR and Hammarberg K (2012). Psychological and social aspects of infertility in men: an overview of the evidence and implications for psychologically informed clinical care and future research. Asian J. Androl. 14: 121-129. http:// dx.doi.org/10.1038/aja.2011.72

Flynn H, Yan J, Saravelos SH and Li TC (2014). Comparison of reproductive outcome, including the pattern of loss, between couples with chromosomal abnormalities and those with unexplained repeated miscarriages. J. Obstet. Gynaecol. Res. 40: 109-116. http://dx.doi.org/10.1111/jog.12133

Frederiksen Y, Farver-Vestergaard I, Skovgård NG, Ingerslev HJ, et al. (2015). Efficacy of psychosocial interventions for psychological and pregnancy outcomes in infertile women and men: a systematic review and meta-analysis. $B M J$ Open 5: e006592. http://dx.doi.org/10.1136/bmjopen-2014-006592

Gana K and Jakubowska S (2014). Relationship between infertility-related stress and emotional distress and marital satisfaction. J. Health Psychol. [Epub ahead of print].

Gao J, Zhang X, Su P, Liu J, et al. (2013). Relationship between sexual dysfunction and psychological burden in men with infertility: a large observational study in China. J. Sex. Med. 10: 1935-1942. http://dx.doi.org/10.1111/jsm.12207

Gollenberg AL, Liu F, Brazil C, Drobnis EZ, et al. (2010). Semen quality in fertile men in relation to psychosocial stress. Fertil. Steril. 93: 1104-1111. http://dx.doi.org/10.1016/i.fertnstert.2008.12.018

Karaca A and Unsal G (2015). Psychosocial problems and coping strategies among Turkish women with infertility. Asian Nurs Res (Korean Soc Nurs Sci) 9: 243-250. http://dx.doi.org/10.1016/j.anr.2015.04.007

Kedem P, Mikulincer M, Nathanson YE and Bartoov B (1990). Psychological aspects of male infertility. Br. J. Med. Psychol. 63: 73-80. http://dx.doi.org/10.1111/j.2044-8341.1990.tb02858.x

Klemetti R, Raitanen J, Sihvo S, Saarni S, et al. (2010). Infertility, mental disorders and well-being--a nationwide survey. Acta Obstet. Gynecol. Scand. 89: 677-682. http://dx.doi.org/10.3109/00016341003623746

Li J, Liu B and Li M (2014). Coping with infertility: a transcultural perspective. Curr. Opin. Psychiatry 27: $320-325$. http://dx.doi.org/10.1097/YCO.0000000000000091

Martins MV, Costa P, Peterson BD, Costa ME, et al. (2014). Marital stability and repartnering: infertility-related stress trajectories of unsuccessful fertility treatment. Fertil. Steril. 102: 1716-1722. http://dx.doi.org/10.1016/j. fertnstert.2014.09.007

Musa R, Ramli R, Yazmie AW, Khadijah MB, et al. (2014). A preliminary study of the psychological differences in infertile couples and their relation to the coping styles. Compr. Psychiatry 55 (Suppl 1): S65-S69. http://dx.doi. org/10.1016/j.comppsych.2013.01.001

Noorbala AA, Ramazanzadeh F, Malekafzali H, Abedinia N, et al. (2008). Effects of a psychological intervention on depression in infertile couples. Int. J. Gynaecol. Obstet. 101: 248-252. http://dx.doi.org/10.1016/j.ijgo.2007.12.010

Omoaregba JO, James BO, Lawani AO, Morakinyo O, et al. (2011). Psychosocial characteristics of female infertility in a tertiary health institution in Nigeria. Ann. Afr. Med. 10: 19-24. http://dx.doi.org/10.4103/1596-3519.76567

Ozawa N, Maruyama T, Nagashima T, Ono M, et al. (2008). Pregnancy outcomes of reciprocal translocation carriers who have a history of repeated pregnancy loss. Fertil. Steril. 90: 1301-1304. http://dx.doi.org/10.1016/j. fertnstert.2007.09.051

Pasch LA, Gregorich SE, Katz PK, Millstein SG, et al. (2012). Psychological distress and in vitro fertilization outcome. Fertil. Steril. 98: 459-464. http://dx.doi.org/10.1016/j.fertnstert.2012.05.023

Peterson BD, Sejbaek CS, Pirritano M and Schmidt L (2014). Are severe depressive symptoms associated with infertilityrelated distress in individuals and their partners? Hum. Reprod. 29: 76-82. http://dx.doi.org/10.1093/humrep/det412

Podolska MZ and Bidzan M (2011). Infertility as a psychological problem. Ginekol. Pol. 82: 44-49.

Ramezanzadeh F, Noorbala AA, Abedinia N, Rahimi Forooshani A, et al. (2011). Psychiatric intervention improved pregnancy rates in infertile couples. Malays. J. Med. Sci. 18: 16-24.

Read SC, Carrier ME, Boucher ME, Whitley R, et al. (2014). Psychosocial services for couples in infertility treatment: what do couples really want? Patient Educ. Couns. 94: 390-395. http://dx.doi.org/10.1016/j.pec.2013.10.025

Venkateshwari A, Srilekha A, Begum A, Sujatha M, et al. (2011). De novo chromosomal translocation t(3;5)(q13;q35) in 
an infertile man. Andrologia 43: 428-430. http://dx.doi.org/10.1111/j.1439-0272.2010.01069.x

Vozdova M, Oracova E, Musilova P, Kasikova K, et al. (2011). Sperm and embryo analysis of similar $\mathrm{t}(7 ; 10)$ translocations transmitted in two families. Fertil. Steril. 96: e66-e70. http://dx.doi.org/10.1016/j.fertnstert.2011.04.042

Wischmann T, Scherg H, Strowitzki T and Verres R (2009). Psychosocial characteristics of women and men attending infertility counselling. Hum. Reprod. 24: 378-385. http://dx.doi.org/10.1093/humrep/den401

Zhang HG, Liu XY, Hou Y, Chen S, et al. (2015). Reproductive outcome of a case with familial balanced translocation t(3;6): implications for genetic counseling. Genet. Mol. Res. 14: 2809-2815. http://dx.doi.org/10.4238/2015. March.31.11

Zorn B, Auger J, Velikonja V, Kolbezen M, et al. (2008). Psychological factors in male partners of infertile couples: relationship with semen quality and early miscarriage. Int. J. Androl. 31: 557-564. http://dx.doi.org/10.1111/j.1365$\underline{2605.2007 .00806 . x}$ 